\title{
Water relation characteristics and photosynthesis of saline-stressed seedlings of non-halophyte species
}

\author{
T. Suzaki, H. Yahata and H. Shigenaga \\ Laboratory of Silviculture, Department of Forestry, Faculty of Agriculture, Kyushu University, \\ Fukuoka, Japan
}

\section{Introduction}

Most plants show growth retardation at low salinity and die in high salinity. The causes are considered to be mainly water stress and/or ion excess. Plants may be able to cope with an adverse water relation, if they absorb salts in leaf cells to adjust osmotically. But, without efficient compartmentation in vacuoles or exclusion of excessive salt in osmotic adjustment, which are recognized in halophytes, plants will suffer from ion excess. The objective of the present study was to examine the distribution of salts and its effect on photosynthesis for non-halophyte woody species. In addition, the contribution of sodium and chloride to osmotic adjustment is discussed.

\section{Materials and Methods}

The seedlings of each species, Osmanthus asiaticus var. aurantiacus, Distylium racemosum, Cinnamomum camphora and Euonymus japonicus were established in 1/5000 a Wagner pots. Salt treatments $(0,5,10,20$ and $40 \%$ artificial seawater) were imposed by daily irrigation of $100 \mathrm{ml}$ for $40 \mathrm{~d}$. Time-course changes in photosynthetic rates were determined using an open gas-exchange system with an infrared gas analyzer. The conditions of measurement were that light intensity was $40 \mathrm{klx}$, leaf temperature was $25^{\circ} \mathrm{C}$, and the air flow rate was $1.2 \mathrm{l} / \mathrm{min}$. Pressure-volume curves were constructed at the termination of treatment. After treatment, sodium, potassium and chloride concentrations were determined for leaves, stem, main root and fine roots. Sodium and potassium were estimated by flame photometry. Chloride was determined by silver ion titration.

\section{Results}

Time course changes in photosynthetic rates were shown as relative values against $0 \%$ treatment. Photosynthesis by $O$. asiaticus var. aurantiacus decreased progressively as the salinity level increased and time lapsed (Fig. 1a). In $D$. racemosum, the lower salinity treatments stimulated photosynthesis on d 10. After that, while declining substantially above $20 \%$ treatment, it remained high in $10 \%$ and $5 \%$ treatments (Fig. ib). in C. cam- 

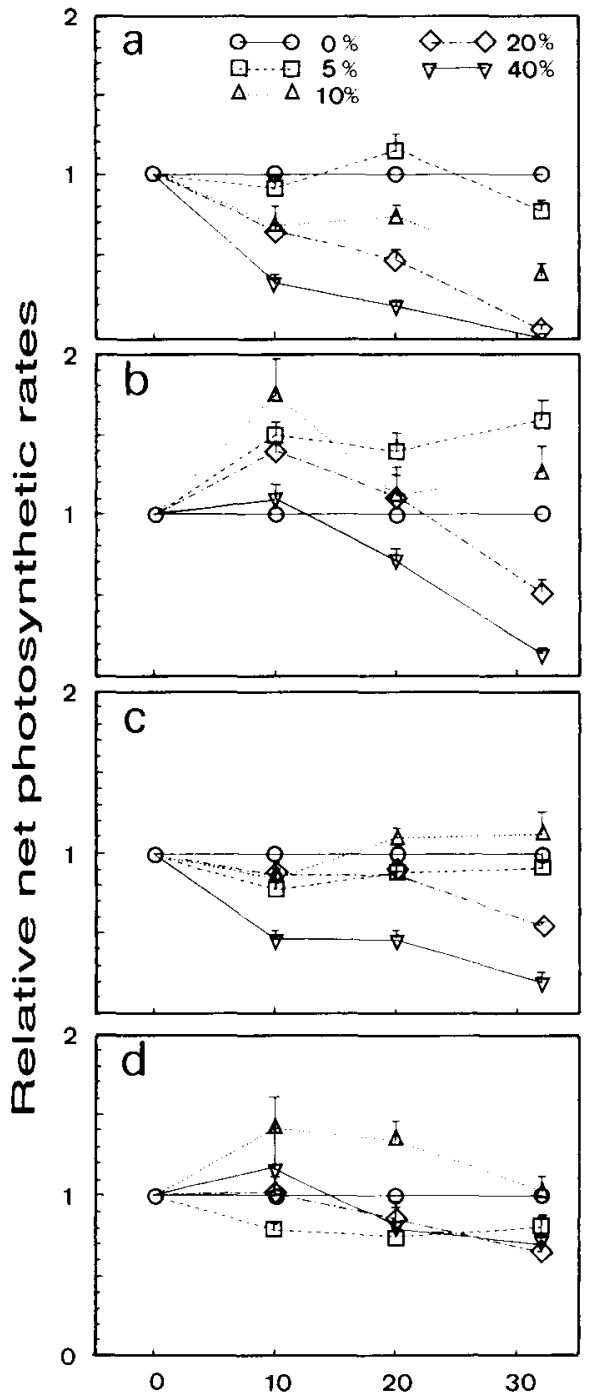

Time (days)

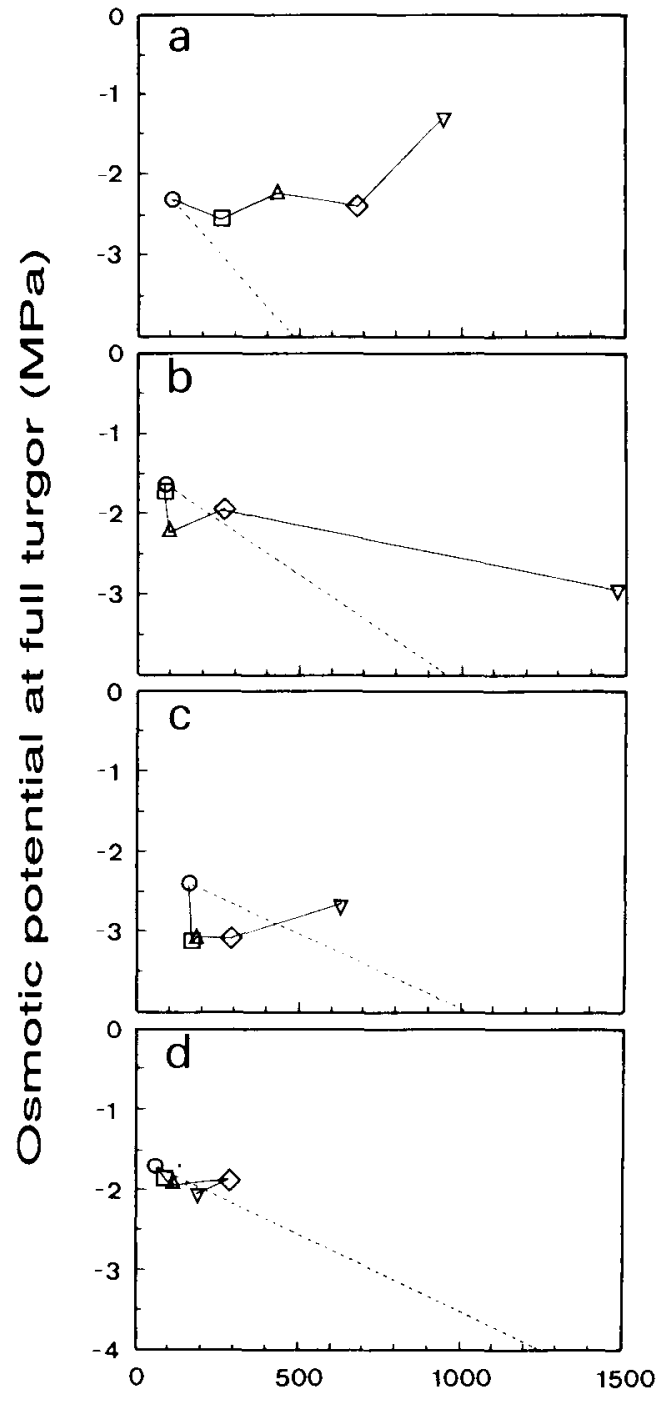

$\mathrm{Na}+\mathrm{Cl}$ concentration in leaves $(\mu \mathrm{mol} / \mathrm{g} \mathrm{DW})$
Fig. 1. Time course changes in relative net photosynthesis by (a) Osmanthus asiaticus var, aurantiacus, (b) Distylium racemosum, (c) Cinnamomum camphora and (d) Euonymus japonicus treated with different concentrations of artificial seawater.
Fig. 2. Measured and calculated (broken line) relationships between the $\mathrm{Na}$ and $\mathrm{Cl}$ concentration and osmotic potential at full turgor (refer to Fig. 1 for symbols). 
phora, there were no significant effects under $10 \%$ treatment but gradual decreases above $20 \%$ (Fig. 1c). E. japonicus showed some decreases for higher salt treatments, which were less compared to the other species (Fig. 1d).

The extent of sodium accumulation in leaves and fine roots showed marked differences between $O$. asiaticus var. aurantiacus and the other 3 species. In $O$. asiaticus var. aurantiacus, sodium concentrations in leaves increased as the salt level increased. The other 3 species maintained low concentrations for lower salt treatments, but further treatments caused increases. However, that in fine roots for lower salt treatment increased in the order: $O$. asiaticus var. aurantiacus, $E$. japonicus, $D$. racemosum, and $C$. camphora. Stem and main root concentrations tended to increase gradually in all 4 species. On the other hand, the changes of sodium concentration per whole plant tissues, which indicated the differences in the amounts of absorption, showed similar increases in all 4 species except for $40 \%$ treatment.

The changes in the chloride concentration were similar to that of sodium.

There were no clear concentration differences among the species for potassium.

The relative values of net photosynthetic rates on $d 32$ tended to decrease as the sodium concentration in leaves increased.

The changes of sodium and chloride concentration in leaves and of osmotic potential at full turgor are compared (Fig. 2). The broken line represents the calculated value of osmotic potential under the assumption that all sodium and chloride are sequestered in cells and generate osmotic potential. O. asiaticus var. aurantiacus maintained an almost constant osmotic potential, but increased the potential at high concentration in leaves (Fig. 2a). In D. racemosum and C. camphora, it decreased for lower salt treatments (Fig. $2 b, c)$. These reductions were considered to be caused mainly by other solutes and not by sodiurn or chloride. At the higher concentration, osmotic potential became higher than that of the calculated value. $E$. japonicus seemed to use sodium and chloride for osmotic adjustment, while, in this situation, the sodium and chloride concentration in leaves was low (Fig. 2d).

\section{Discussion and Conclusion}

$O$. asiaticus var. aurantiacus, which accumulated more sodium and chloride in its leaves, showed conspicuous decreases of photosynthesis. However, the other species, except for the seedlings subjected to higher salt treatments, did not show conspicuous reduction of photosynthesis under the low sodium and chloride concentration in leaves. Therefore, it is considered that salt tolerance depends upon an ability to avoid the accumulation of salts in leaves. This ability seems to be attained mainlly by sequestering salts in fine roots to alter the distribution. It is known that the characteristics of salt distribution differ in species (Grieve and Walker, 1983). Walker (1986) reported that the mechanism to avoid the accumulation of sodium in leaves in trifoliate orange existed in proximal root and basal stem, which withdraw sodium from the transpiration stream. Suberized endoderms located in fine roots are considered to have selective permeability, which acts as a barrier to the flow of soluble salts into xylem. Further study, to determine whether structural differences in fine roots exist between species, may be required.

As for the primary cause of death of leaves, the possibility that excessive accumulation of salts in apoplast brings about 
dehydration of cells was discussed (Munns and Passioura, 1984). If the salt concentration increases outside the living cells, the value of osmotic potential at full turgor may be estimated experimentally to be higher than the true value. Therefore, the high osmotic potential calculated above suggests that ion accumulation in apoplast occurred. It might be considered that for non-halophytes, absorbing salts in leaves does not seem to be useful for osmotic adjustment, although it might contribute to some extent but only at low concentrations.

\section{References}

Grieve A.M. \& Walker R.R. (1983) Uptake and distribution of chloride, sodium and potassium ions in salt-treated citrus plants. Aust. J. Agric. Res. 34, 133-143

Munns R. \& Passioura J.B. (1984) Effect of prolonged exposure to $\mathrm{NaCl}$ on the osmotic pressure of leaf xylem sap from intact, transpiring barley plants. Aust. J. Plant Physiol. 11, 497507

Walker R.R. (1986) Sodium exclusion and potassium-sodium selectivity in salt-treated trifoliate orange (Poncirus trifoliata) and Cleopatra mandarin (Citrus reticulata) plants. Aust. J. Plant Physiol. 13, 293-303 